\title{
Three new species of Osmylus Latreille from China (Neuroptera, Osmylidae)
}

\author{
Han Xu', Yongjie Wang'2, Zhiqi Liu' \\ I Department of Entomology, China Agricultural University, Beijing 100094, China 2 College of Life Sciences, \\ Capital Normal University, Beijing 100048, China \\ Corresponding authors: Yongjie Wang (wangyjosmy@foxmail.com); ZhiqiLiu (zhiqiliu@cau.edu.cn)
}

Academic editor: S. Winterton | Received 26 November 2015 | Accepted 28 March 2016 | Published 16 May 2016

http://zoobank.org/E7489ECB-E933-445C-9CE4-EFEC8D7393F9

Citation: Xu H, Wang Y, Liu Z (2016) Three new species of Osmylus Latreille from China (Neuroptera, Osmylidae). ZooKeys 589: 107-121. doi: 10.3897/zookeys.589.7320

\begin{abstract}
Three new species of Osmylus Latreille are described from China: Osmylus maoershanicola sp. n., Osmylus shaanxiensis sp. n. and Osmylus angustimarginatus sp. n. These new species are distinguishable from other related species by the shape of the $9^{\text {th }}$ tergite of both sexes, as well as the shape of gonarcus, mediuncus and spermatheca. A key is given to differentiate Palaearctic and Oriental species of Osmylus.
\end{abstract}

\section{Keywords}

New species, Oriental region, Osmylidae, Osmylus, Palaearctic region

\section{Introduction}

The genus Osmylus Latreille (Osmylidae: Osmylinae) contains 21 species distributed in the Palaearctic and Oriental regions, 20 species of which are distributed in Asia and only one, O. fulvicephalus, which is widespread in Europe (Banks 1947, Canbulat 2013, Iwata 1928, Kozhanchikov 1951, Krüger 1912, 1913, Makarkin 1985, McLachlan 1870, 1875, Nakahara 1914, New 1991, Yang 1987, 1988, 1997, 1999). The first Osmylus species of the Chinese fauna, Osmylus (Lysmus) oberthurinus, was described 


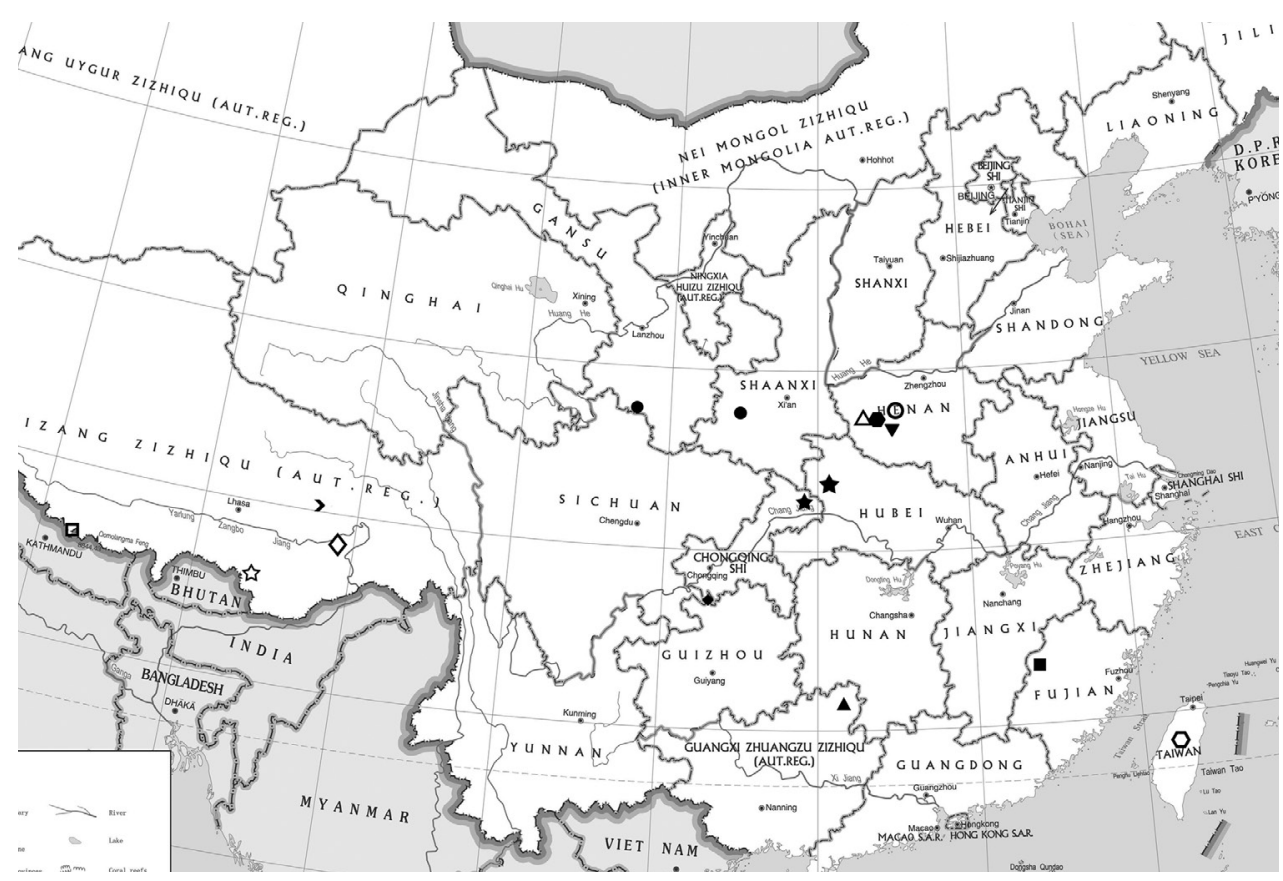

Figure I. Distribution of Osmylus in China. $\$$ = . angustimarginatus sp. n.; $\triangle=O$. biangulus; $\boldsymbol{\nabla}=$

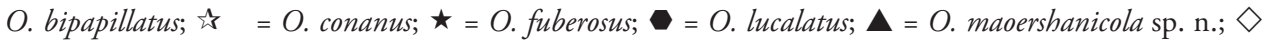
$=O$. megistus; $\square=O$. minisculus; $\mathrm{O}=O$. shaanxiensis sp. n.; $\square=O$. taiwanensis; $\boldsymbol{\square}=O$. wuyishanus; $>$ $=$ O. xizangensis.

by Navás (1910) and then 12 species described successively by Banks (1947), Yang (1987, 1988, 1997, 1999) and Wang and Liu (2010), with higher diversity in Tibet (four species) and Shaanxi Province (four species) (Fig. 1).

The biology of osmylids is still poorly known. Osmylus is known to be univoltine and adults feed as generalists on fungal spores, pollen, algae, mites and insects; they sit temporarily on foliage of plants along streams or river banks in daytime (Devetak 2007, Gepp 1976, Withycombe 1923). The biology of larvae remains controversial. Latreille (1805) and Stein (1838) deduced that the larvae of Osmylus are aquatic. However, Stitz (1936) and Eisner (1989) reported correctly that the larvae simply live in the water margin (the riparian interface) but cannot survive submersion. Accordingly, the larvae should definitely be regarded as terrestrial.

\section{Materials and methods}

The specimens in this study were examined under an Optec SZ760 stereomicroscope with direct light. The terminal of abdomens were removed and soaked in the $10 \%$ $\mathrm{NaOH}$ for boiling water bath and stored in a glycerin-filled micro-vial mounted on 
the pin beneath specimen. The terminology for wing venation and genitalia follows New (1983), Adams (1969) and New (1983). All type specimens are deposited in the Entomological Museum of China Agricultural University (CAU), Beijing.

\section{Taxonomy}

\section{Genus Osmylus Latreille}

Osmylus Latreille, 1802: 289. Type species: Hemerobius fulvicephalus Scopoli, 1763: 270. Dictyosmylus Navás, 1910: 189. Type species: Dictyosmylus lunatus Navás, 1910: 189, by monotypy.

Diagnosis. Moderate to large body size (body length $15-20 \mathrm{~mm}$ ); forewing generally large and broad (length $20-30 \mathrm{~mm}$ ), with numerous fragmentary marks; two nygmata present at the center and the proximal base of wing between MP and Rs; veins dark brown; costal cross-veins generally bifurcate distally, without interlinking veinlets; crossveins among branches of Rs forming at least two series of gradates; MP forked close to the base, $\mathrm{MP}_{2}$ with many branches. The hindwing resembles the forewing in shape, but with fewer spots. The $9^{\text {th }}$ tergite has variably-shaped dorsal process. Genitalia are composed of a gonarcus and a mediuncus; the gonarcus is variable in shape, consisting of a sclerotized and pilose external section posteriorly with a lightly sclerotized anteriorlateral section, the latter laterally with an anterior rod shaped process (i.e., baculum of some authors) which is sometimes articulated. The mediuncus (i.e., parameres of some authors) is curved with a fused base (although the shape is variable in $O$. pachycaudatus). The mediuncus is subtended laterally by the rod-shaped, paired parameres (i.e., subarcus of other authors) that are not fused anteriorly. The female $9^{\text {th }}$ tergite occasionally has a ventral process, the gonapophysis lateralis is generally finger-like and articulated with stylus distally, and the spermatheca is either oval or cylindrical in shape.

Included species. Osmylus angustimarginatus sp. n., O. biangulus Wang \& Liu, O. bipapillatus Wang \& Liu, O. cilicicus Krüger, O. conanus Yang, O. decoratus Nakahara, O. fuberosus Yang, O. fulvicephalus (Scopoli), O. gussakovskii Kozhanchikov, O. hyalinatus McLachlan, O. kisoensis Iwata, O. lucalatus Wang, O. maoershanicola sp. n., O. megistus Yang, O. minisculus Yang, O. multiguttatus McLachlan, O. pachycaudatus Wang, O. posticatus Banks, O. pryeri McLachlan, O. shaanxiensis sp. n., O. taiwanensis New, O. tessellatus McLachlan, O. wuyishanus Yang, O. xizangensis Yang.

Comments. Osmylus has been often confused with three other genera, Grandosmylus Makarkin, 1985, Parosmylus Needham, 1909 and Plethosmylus Krüger, 1913. Banks (1913) advanced that Parosmylus should be a junior synonym of Osmylus because the spur on the coxa in Parosmylus is also present in some species of Osmylus. Krüger (1913) erected the genus Plethosmylus based on venation characters (presence of interlink veinlets between costal cross-veins). Nakahara (1914) considered the opinion of Krüger subjective and synonymized the latter genus. Kuwayama $(1953,1962)$ 
again separated Plethosmylus, differentiating it from Osmylus by the presence of interlinking veinlets among the costal and two basal Rs-Mp cross-veins before the proximal nygma. However, Makarkin (1985) revised the status of Plethosmylus, synonymizing it with Osmylus and establishing a new subgenus Plesiosmylus within Osmylus. He also established a new genus Grandosmylus, separated from Osmylus by the irregular gradate cross-veins and the shape of $9^{\text {th }}$ sternite in males and $8^{\text {th }}$ sternite in females; this opinion was accepted by Sekimoto (2011) in his revision of Japanese Osmylus. The relationship among Grandosmylus, Parosmylus and Plethosmylus remains unclear. Wang and Liu (2009) clarified the generic status of Parosmylus, after reviewing specimens from mainland China, and they concluded that both genera could be valid due to differences in the number of gradate series, the configuration of gonarcus and the shape of spermatheca (Wang and Liu 2009). Furthermore, after re-examining the specimens of Plethosmylus from mainland China, we observed that Osmylus and Plethosmylus possessed significant differences in male genitalia (the configuration of gonarcus) and in female genitalia. Moreover, the interlink veinlets among costal cross-veins could conveniently divide them. Considering the vague relationships among these genera, we consider is suitable to maintain them as separate genera until a robust phylogenetic work can be conducted in the future. In this paper, three new species of Osmylus are described from China: O. maoershanicola sp. n. O. shaanxiensis sp. n. and O. angustimarginatus sp. n., primarily based on genital characters.

\section{Key to Osmylus species in the Palaearctic and Oriental regions}

(Note: Osmylus kisoensis is not included as it is only known from the larval stage, while $O$. cilicicius and $O$. posticatus are poorly known and could not be included in the key.)

1 The structure of spermatheca complicated (Fig. 2a) O. megistus

- $\quad$ The structure of spermatheca simple (Fig. 2b-h)..... 2 The $7^{\text {th }}$ sternite in female with a median preapical protuberance .................. 3 The $7^{\text {th }}$ sternite in female without any protuberance. Spermatheca cylindrical and bent; anterior third of pronotum with median stripe.

O. taiwanensis

Spermatheca oval; frons with dark brown X-shaped marking; pronotum with yellow and median stripe O. decoratus The gonapophyses lateralis cone-shaped, spermatheca pyriform ... O. minisculus The gonapophyses lateralis finger-like or fusiform .5 $9^{\text {th }}$ tergite in male with a distinct dorsal process (Figs 3a-d, 5a, 9a)

6 Gonarcus with a sharpened process along dorsal margin in lateral view.....

- Gonarcus without processes along dorsal margin in lateral view...... .7 Forewing relatively narrow, membrane hyaline with slight metallic luster..... 

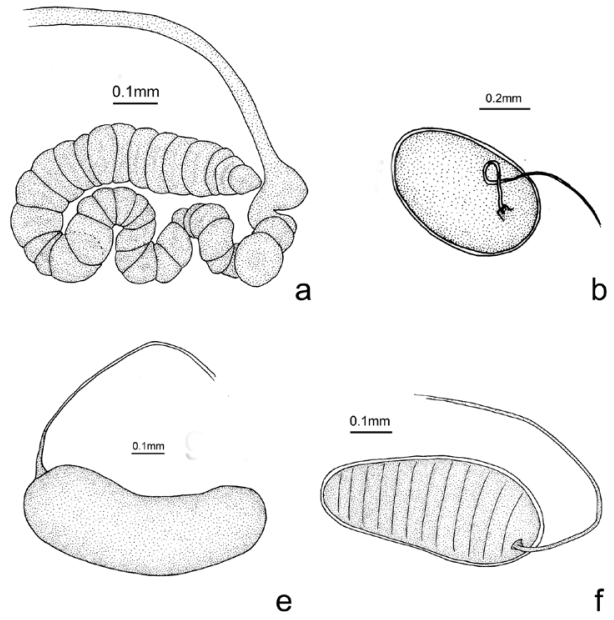

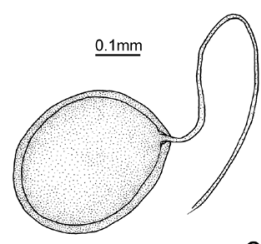

C

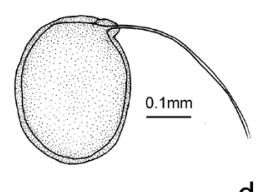

d

Figure 2. Spermathecae. a $O$. megistus b $O$. lucalatus $\mathbf{c} O$. angustimarginatus sp. n. d $O$. maoershanicola sp. n. e O. biangulus $\mathbf{f} O$. fuberosus $\mathbf{g} O$. shaanxiensis sp. n. h $O$. wuyishanus.

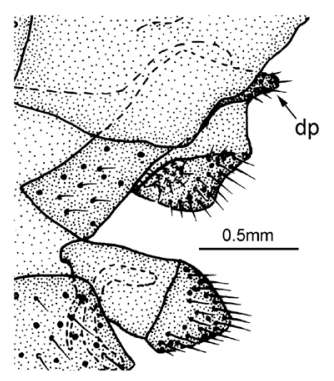

a

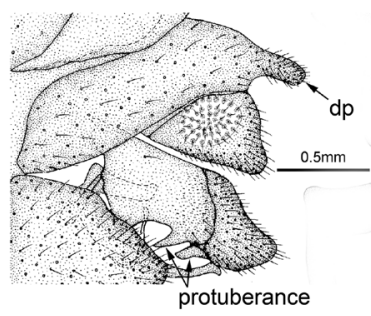

b

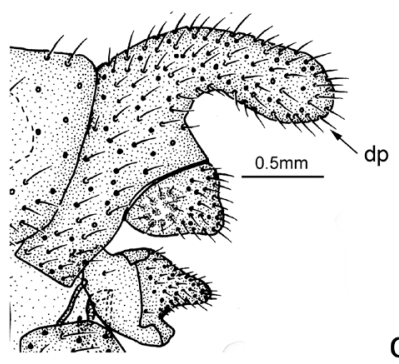

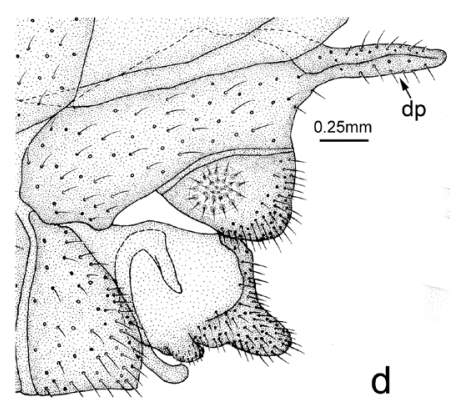

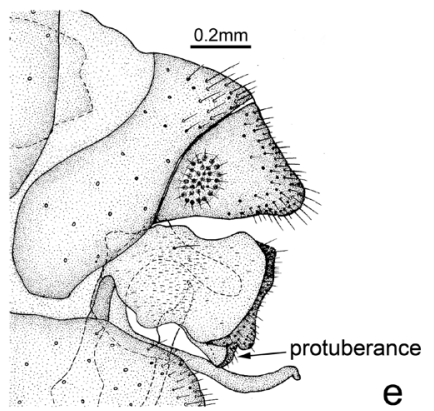

Figure 3. Male terminalia, lateral view. a $O$. lucalatus b $O$. biangulus c $O$. pachycaudatus $\mathbf{d} O$. bipapillatus e $O$. fuberosus. Abbreviation: dp, dorsal process.

- $\quad$ Forewing broad, membrane dull hyaline 8 The length of process of $9^{\text {th }}$ tergite in male slightly longer than width (Figs $3 \mathrm{~b}$, 5a, 9a). 
- $\quad$ The length of process of $9^{\text {th }}$ tergite in male significantly longer than width (Fig. 3c-d)

10 Gonarcus with one or two lateral posteroventral protuberances .................11

Gonarcus without any lateral posteroventral protuberance.

11 Gonarcus with only one lateral posteroventral protuberance in lateral view (Fig. 5b) O. maoershanicola sp. $\mathrm{n}$. Gonarcus with two lateral posteroventral protuberances in lateral view (Fig. 3b)

O. biangulus

12 Mediuncus apically hook-shaped O. fulvicephalus Mediuncus apically slender and straight (Fig. 5d)...O. angustimarginatus sp. $\mathbf{n}$.

13 The process of $9^{\text {th }}$ tergite in male cylindrical (Fig. 3c), mediuncus arch-like in lateral view, anterior arm of gonarcus with a distal right-angle bend

O. pachycaudatus

The process of $9^{\text {th }}$ tergite in male subulate (Fig. 3d), mediuncus C-shaped in lateral view

O. bipapillatus

Distal part of gonarcus flat and quadrate, with a posteroventral protuberance (Fig. 3e) O. fuberosus

- Distal part of gonarcus approximately triangular 15 $8^{\text {th }}$ sternite in female with two ventral protuberances; distal part of gonarcus with a ventral and rod-like protuberance. $8^{\text {th }}$ sternite in female without any protuberance

17 Distal part of gonarcus with two protuberances in later view; pronotum with slender yellow marking on anterior half and yellow spot over posterior margin

- Distal part of gonarcus with only one protuberance

18 Cross-veins among branches of Rs forming 3 series of gradates; forewing and hindwing with approximately rounded spots O. multiguttatus

- $\quad$ Cross-veins among branches of Rs forming 2 series of gradates 19

$199^{\text {th }}$ tergite in female with a median narrowing in lateral view (Fig. 7e); mesoand metanotum dark brown, some sclerites brown .... O. shaanxiensis sp. $\mathbf{n}$. $9^{\text {th }}$ tergite in female slightly tapered medially in lateral view; meso- and metanotum yellowish brown with black streaks

O. xizangensis

20 Distal part of gonarcus forming a large triangular sclerite; outer gradates of forewing with brown marks ....

O. wuyishanus

- Distal part of gonarcus forming a narrow and small sclerite; inner gradates of forewing with brown marks

O. conacus 


\section{Osmylus maoershanicola sp. $\mathbf{n}$.}

http://zoobank.org/515687EC-B4FF-489C-A12D-4B41DEC81A34

Figs 4, 5

Material examined. Holotype Male, CHINA: Guangxi (Province): Maoershan (Na-

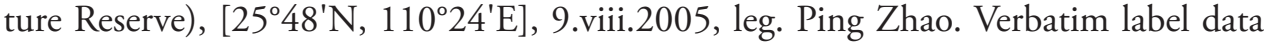
(translated from Chinese): CHINA: Guangxi Prov., Maoershan/ 9.viii.2005/ Ping Zhao/ CAU. Condition: Antennal flagellum missing. Abdomen terminalia cleared in $\mathrm{KOH}$, and stored in the micro-vial pinned below the specimen. Paratype. 1 female (left antenna damaged), same data as holotype (CAU).

Diagnosis. Male: $9^{\text {th }}$ tergite with a short finger-like dorsal process; ectoproct coneshaped. Gonarcus distally triangular with a ventral, triangular, membranous protuberance in lateral view. Female: gonapophysis lateralis approximately fusiform; spermatheca oval.

Description. Head. Vertex yellowish-brown with brown setae; eye dark gray, ocelli yellow, area within ocelli black. Antennal flagellum missing, scape and pedicel dark brown; frons yellow. Thorax. Pronotum dark brown, posterior margin slightly wider,

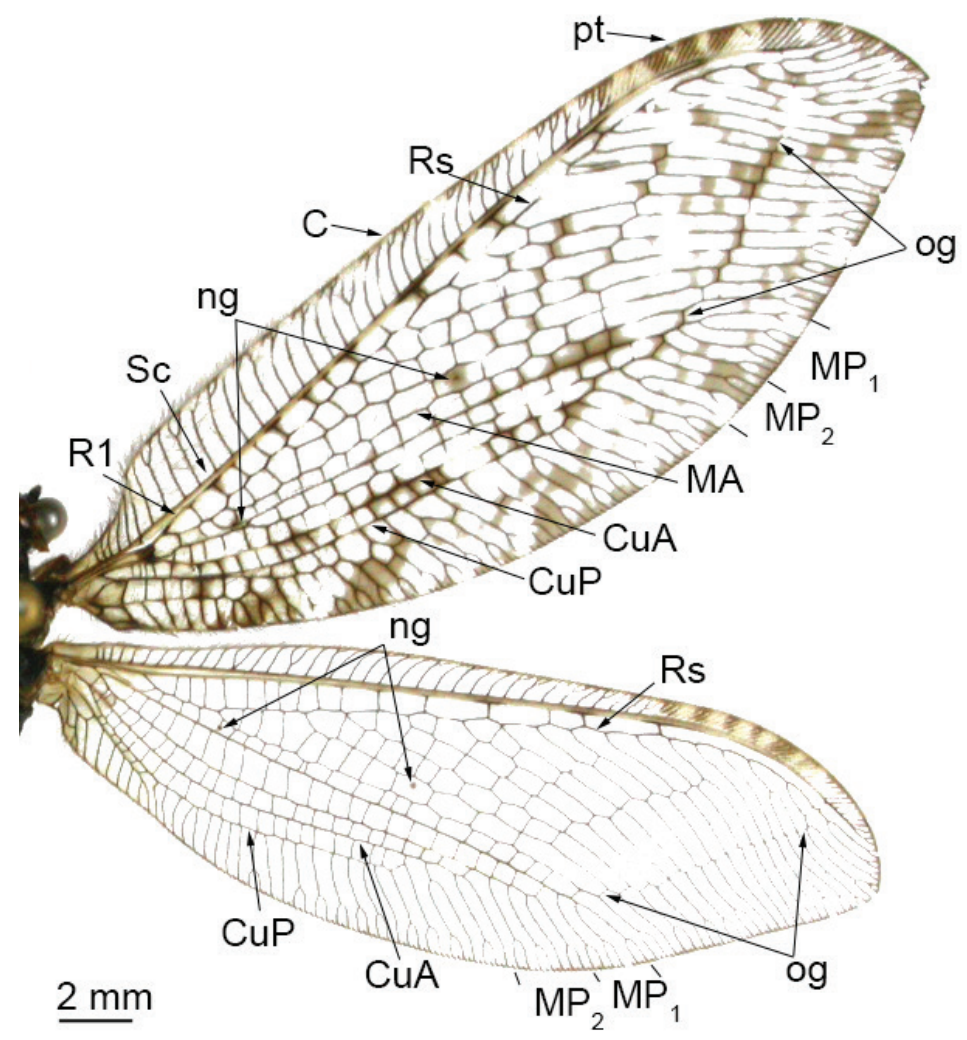

Figure 4. Wings of Osmylus maoershanicola sp. n., forewing (upper) and hindwing (lower). Abbreviations: ng, nygmata; pt, pterostigma; og, outer gradates. 


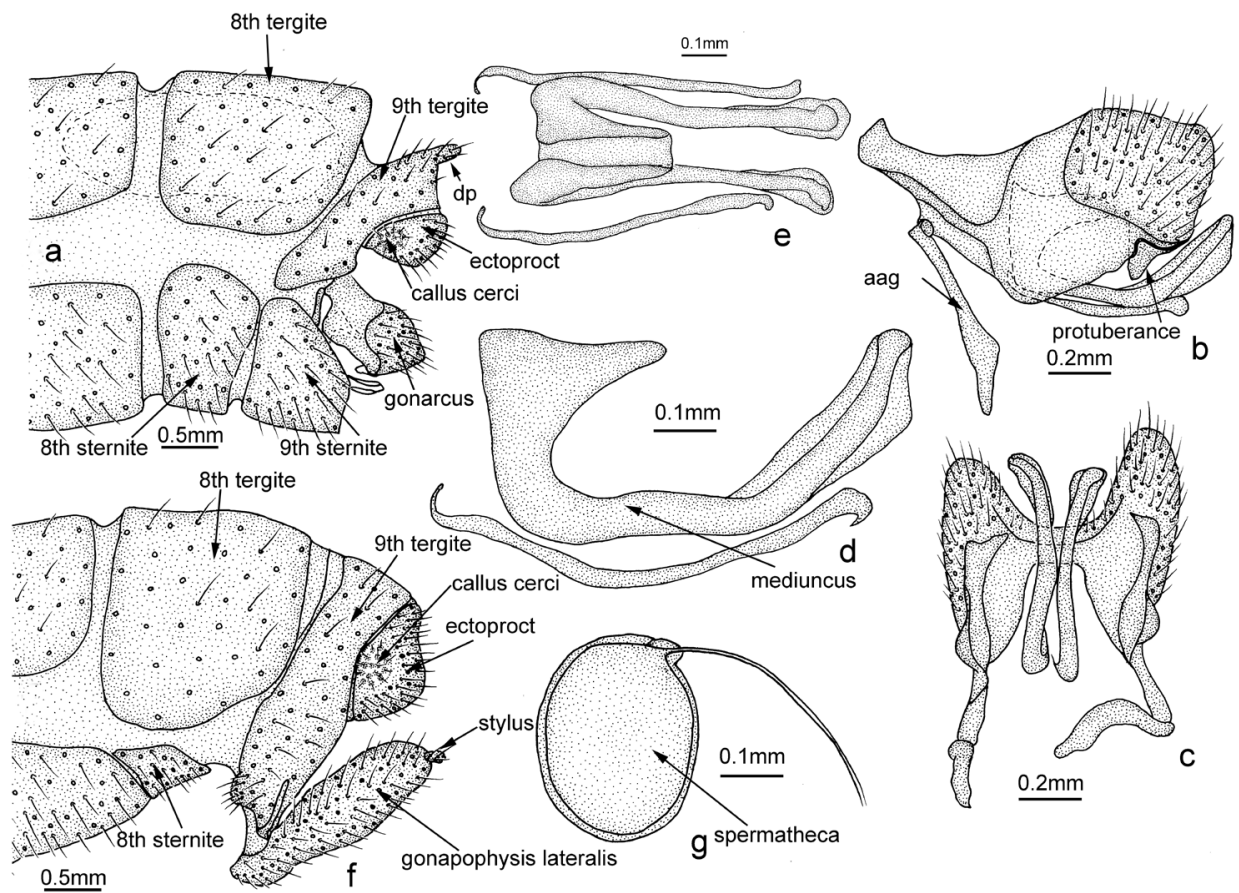

Figure 5. Osmylus maoershanicola sp. n. a-e Male: a apex of the abdomen and genitalia, lateral view b genitalia, lateral view c genitalia, ventral view $\mathbf{d}$ mediuncus, lateral view e mediuncus, dorsal view $\mathbf{f}-\mathbf{g}$ Female: $\mathbf{f}$ apex of the abdomen and genitalia $\mathbf{g}$ spermatheca, lateral view (spiracula omitted). Abbreviation: $\mathrm{dp}$, dorsal process; aag, anterior arm of gonarcus.

with black brown setae; meso- and metanotum black with brown setae. Legs yellow with brown setae; pretarsal claws dark brown.

Wing (Fig. 4). Forewing length 27-28 mm, width 9-10 mm. Membrane hyaline, with many sparse, fuscous spots; pterostigma brown; nygmata light brown; veins dark brown; Rs with 13-14 branches, outer gradate cross-veins edged with fuscous stains; R1-Rs cross-veins edged with brown marks; short cross-veins are present among the branches of CuP. Hindwing length 23-24 mm, width 7-8 mm. Membrane hyaline; pterostigma light yellow.

Male terminalia (Fig. 5a-e). Scent glands slender. $9^{\text {th }}$ tergite long and narrow with a short, dorsal finger-like process (Fig. 5a), ventral margin slightly tapered. $9^{\text {th }}$ sternite trapezoidal in lateral view. Ectoproct triangular in lateral view, callus cerci round. Distal part of gonarcus well sclerotized and approximately triangular, ventral part membranous with a triangular protuberance in lateral view (Fig. 5b); anterior arm of gonarcus slender; mediuncus dilated basally with a sharp backward end, slender apically and coated by a membrane in lateral view; rod-shaped paramere beneath the mediuncus slightly bent in lateral view, posterior end sharp. 
Female terminalia (Fig. 5f-g). $8^{\text {th }}$ sternite approximately trapezoidal; $9^{\text {th }}$ tergite long and narrow with a ventral hemispherical tubercle in lateral view; ectoproct triangular in lateral view, callus cerci round, presenting in middle; gonapophysis lateralis approximately fusiform, stylus cylindrical; spermatheca simple, approximately spherical.

Distribution. Presently known only from Guangxi Province, China.

Etymology. The specific name 'maoershanicola' refers to 'Maoershan Mountain', the type locality.

Remarks. The dorsal finger-like process of $9^{\text {th }}$ tergite of Osmylus maoershanicola sp. n. is similar to $O$. pryeri and $O$. biangulus, but this new species can be identified by the distinctive shape of the gonarcus. There are two prominent ventral protuberances in the distal part of gonarcus of $O$. pryeri and O. biangulus (Fig. 3b) but only one in $O$. maoershanicola sp. n. (Fig. 5b). Furthermore, the distal gonarcus is cone-shaped in $O$. biangulus but triangular in $O$. maoershanicola and the spermatheca is short and bent rod-like in $O$. biangulus (Fig. 2e) but approximately spherical in $O$. maoershanicola (Fig. 5g).

\section{Osmylus shaanxiensis sp. $\mathrm{n}$.}

http://zoobank.org/0815CDFE-15C7-4C26-AC13-46F03D535A44

Figs 6, 7

Material examined. Holotype Male. CHINA: Shaanxi (Province): Houzhenzi (town),

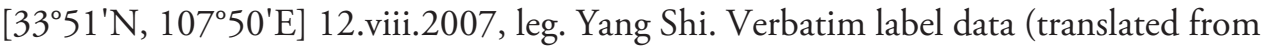
Chinese): CHINA: Shaanxi, Houzhenzi/ 12.viii.2007/ Yang Shi/ CAU. Condition: Antennal flagellum missing. Terminalia cleared in $\mathrm{KOH}$, and stored in the microvial pinned below the specimen. Paratype. 1 female, same data as holotype (CAU).

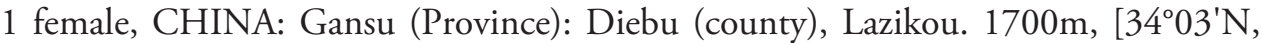
$\left.103^{\circ} 54^{\prime} \mathrm{E}\right]$ 12.viii.1980, Chikun Yang (CAU).

Diagnosis. Wing broad, with numerous dark brown spots on the margin. Male: $9^{\text {th }}$ tergite with a median narrowing, with a small tuberous dorsal process in lateral view; protuberance of posteroventral gonarcus papillary. Base of mediuncus knifeshaped in lateral view. Female: gonapophysis lateralis basally fused with a triangular sclerite, spermatheca bent, cylindrical.

Description. Head. Vertex dark brown. Ocelli yellow, area comprised among ocelli dark brown, eye dark brown; frons brown. Thorax. Pronotum dark brown with yellow long setae; meso- and metanotum dark brown. Legs yellow with dark yellow setae, pretarsal claws dark brown.

Wings (Fig. 6). Forewing length 22-25 mm, width 8-9 mm. Membrane hyaline, with numerous dark brown spots on the margin; pterostigma and nygmata brown; veins dark brown, some edged with dark brown spots; Rs with 12-13 branches, gradates cross-veins with brown marks. Hindwing length $20-22 \mathrm{~mm}$, width 7-8 $\mathrm{mm}$. Membrane hyaline; pterostigma light brown. 


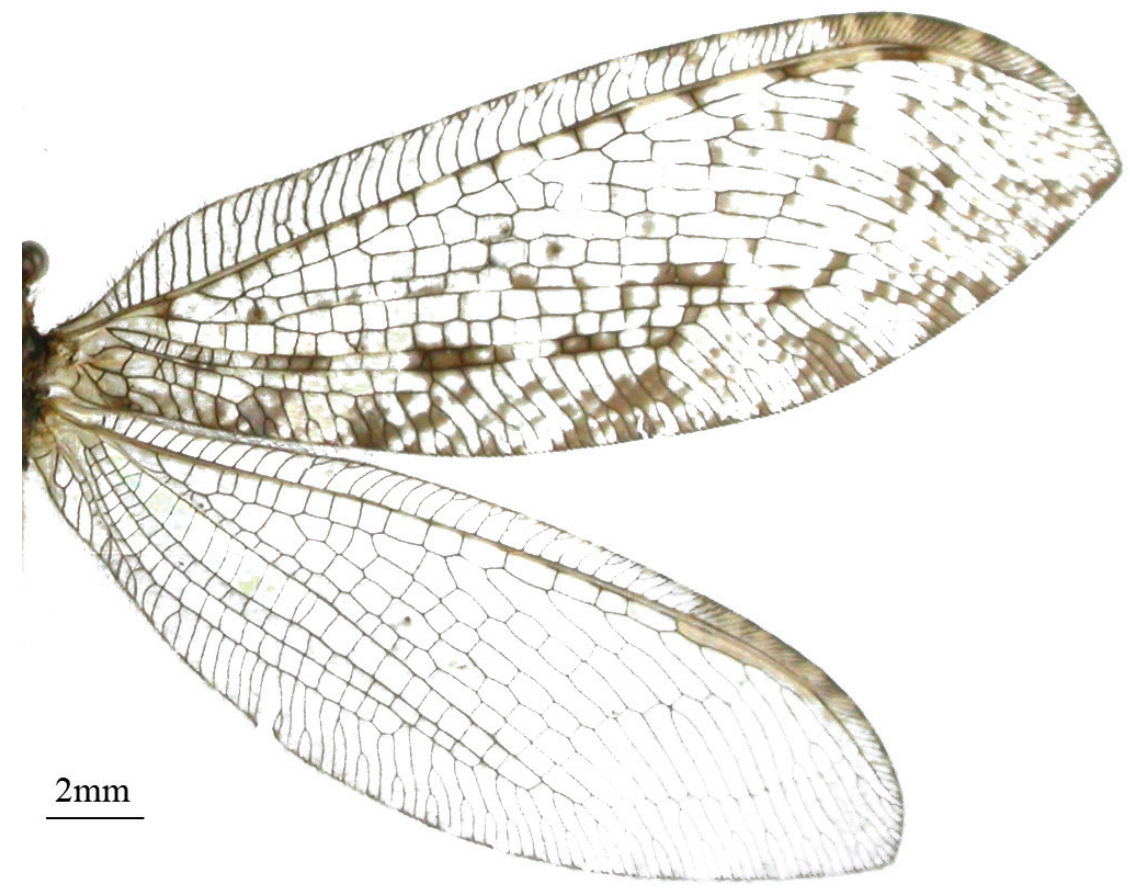

Figure 6. Wings of Osmylus shaanxiensis sp. n., forewing (upper) and hindwing (lower).

Male Terminalia (Fig. 7a-d). Scent glands stout; $9^{\text {th }}$ tergite with a median narrowing in lateral view, with a small hemispheric dorsal process; ectoproct triangular in lateral view, callus cerci oval; gonarcus sclerotized distally and posteroventrally ending into a papilla in lateral view; anterior arm of gonarcus slender, basally dilated; mediuncus basally dilated, knife-shaped, more slender apically in lateral view; rod-shaped paramere slender and bent in lateral view, dilating from base to end.

Female Terminalia (Fig. 7e-f). $8^{\text {th }}$ sternite reduced; $9^{\text {th }}$ tergite narrow; ectoproct approximately conical, callus cerci round; gonapophysis lateralis fusiform, apex with a long finger-like stylus; spermatheca cylindrical, bent and slightly dilated basally.

Distribution. China (Shaanxi, Gansu).

Etymology. The specific name 'shaanxiensis' refers to 'Shaanxi Province', the type locality.

Remarks. The new species can be distinguished from other species by the small hemispheric dorsal process of the $9^{\text {th }}$ tergite in male (Fig. 7a). Although O. shaanxiensis sp. n. is similar to $O$. conanus, they can be easily separated by the differences of gonarcus and gonapophysis lateralis. The distal part of gonarcus in $O$. conanus protrudes slightly but the same part in $O$. shaanxiensis sp. n. protrudes significantly in lateral view (Fig. $7 \mathrm{~b}$ ). Also compared with O. conanus, the spermatheca in O. shaanxiensis sp. n. is longer and more bent (Fig. 7f). 


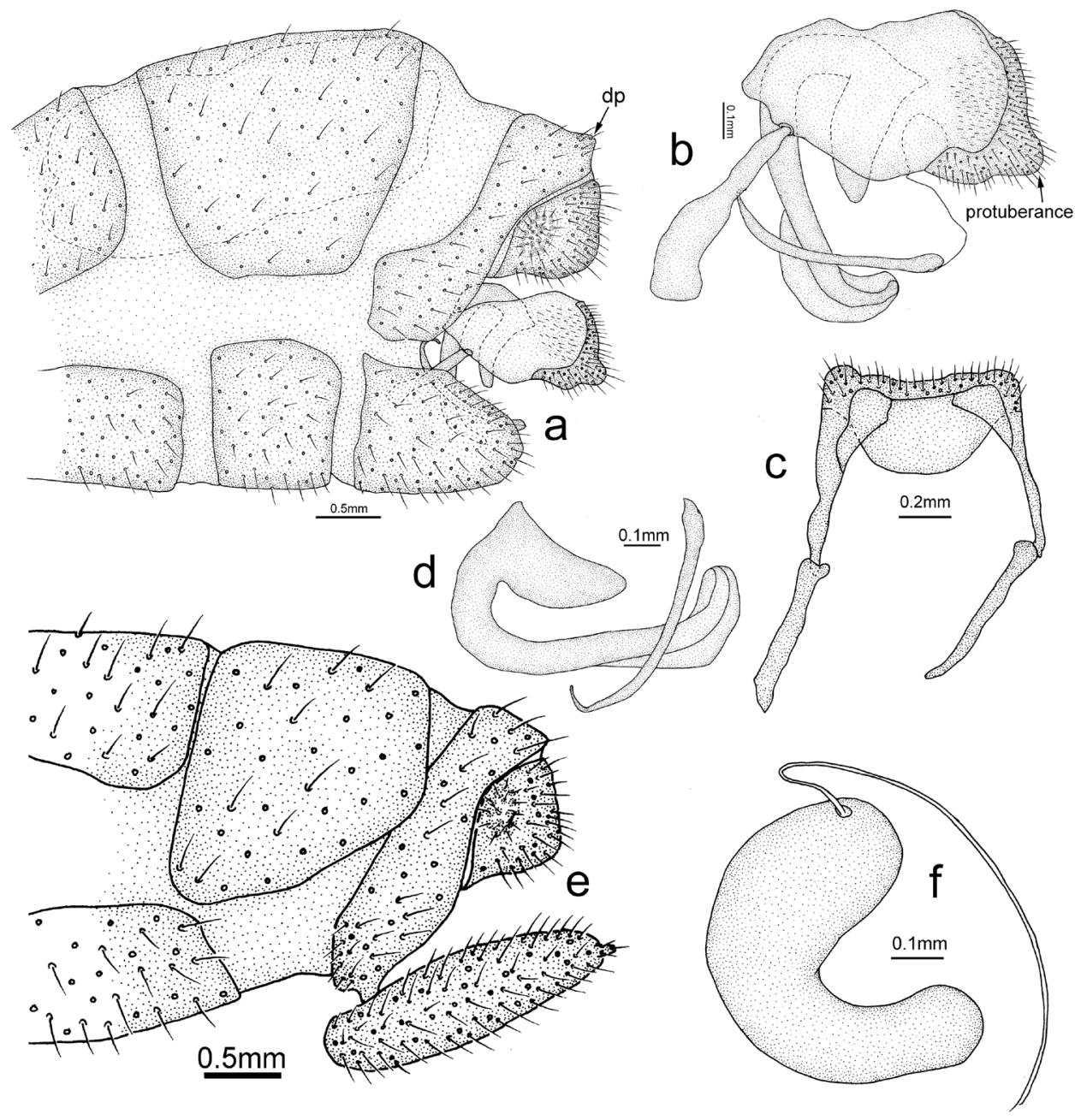

Figures 7. Osmylus shaanxiensis sp. n. a-d Male: $\mathbf{a}$ apex of the abdomen and genitalia $\mathbf{b}$ genitalia, lateral view $\mathbf{c}$ genitalia, ventral view $\mathbf{d}$ mediuncus, lateral view $\mathbf{e - f}$ Female: $\mathbf{e}$ apex of the abdomen and genitalia f spermatheca, lateral view. Abbreviation: dp, dorsal process.

\section{Osmylus angustimarginatus sp. $\mathrm{n}$.}

http://zoobank.org/8018E2FE-CCBB-4BD5-8D9D-B567A84A097A

Figs 8, 9

Material examined. Holotype Male. CHINA: Chongqing: Jiangjin (District): Simianshan (mountain), [28 $\left.38^{\prime} \mathrm{N}, 106^{\circ} 24^{\prime} \mathrm{E}\right]$ 17.vi.2006, leg. Weiwei Zhang. Verbatim label data (translated from Chinese): CHINA: Chongqing, Jiangjin, Simianshan/ 17.vi.2006/ Weiwei Zhang/ PC. Terminalia cleared in KOH, and stored in a microvial pinned below the specimen. Paratype. 1 female, same data as holotype; 1 male, 1 female, same locality as holotype. 21-23.ix.2007, leg. Weiwei Zhang. 


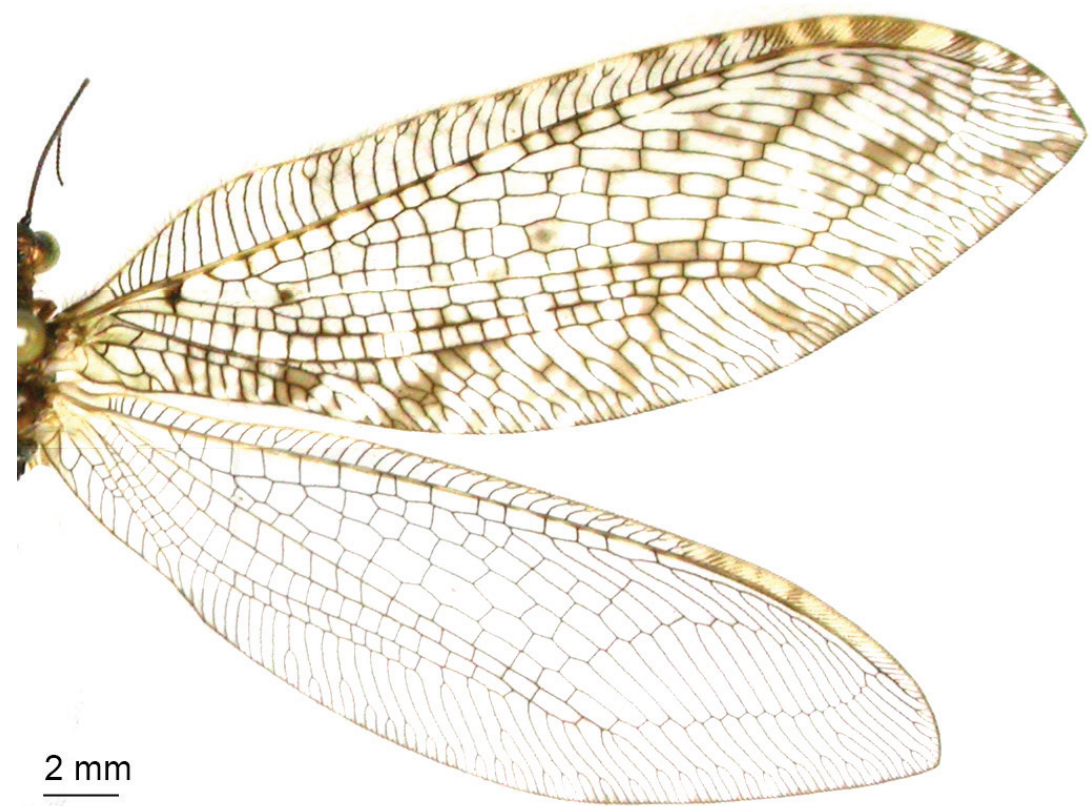

Figure 8. Wings of Osmylus angustimarginatus sp. n., forewing (upper) and hindwing (lower).

Diagnosis. Male: $9^{\text {th }}$ with a finger-like dorsal process. Gonarcus distally triangular in lateral view, ventral margin well sclerotized; base of mediuncus slightly protuberant distally in lateral view. Female: gonapophysis lateralis finger-like; spermatheca approximately spherical.

Description. Head. Vertex yellow brown, with dark brown setae; ocelli light yellow, area comprised among ocelli dark brown; eyes gray with metallic reflection; frons black. Thorax. Pronotum dark brown, with yellow setae; meso- and metanotum fuscous, with black stripes. Legs yellow, with short setae, pretarsal claws dark brown.

Wings (Fig. 8). Forewing length $27-29 \mathrm{~mm}$, width $8-9 \mathrm{~mm}$. Wings elongated; membrane hyaline, with numerous brown spots; pterostigma brown, nygmata light brown; veins dark brown, some edged with dark brown spots; Rs with 13-14 branches; cross-veins are present among branches of CuP. Hindwing length $25-26 \mathrm{~mm}$, width 7-8 mm; membrane hyaline; pterostigma light brown.

Male Terminalia (Fig. 9a-e). Scent glands stout. $9^{\text {th }}$ tergite wide, with a fingerlike process; $9^{\text {th }}$ sternite approximately rectangular in lateral view; ectoproct small, callus cerci round; gonarcus distally well sclerotized and triangular in lateral view, ventral margin well sclerotized; anterior arm of gonarcus slender and basally dilated; mediuncus slightly finger-like at base, more slender apically in lateral view; rod-shaped paramere beneath the mediuncus slightly bent in lateral view.

Female Terminalia (Fig. 9f-h). $8^{\text {th }}$ sternite approximately square in lateral view. $9^{\text {th }}$ tergite narrow; ectoproct conical, callus cerci round; gonapophysis lateralis long and finger-like, with a long conical stylus; spermatheca approximately spherical. 


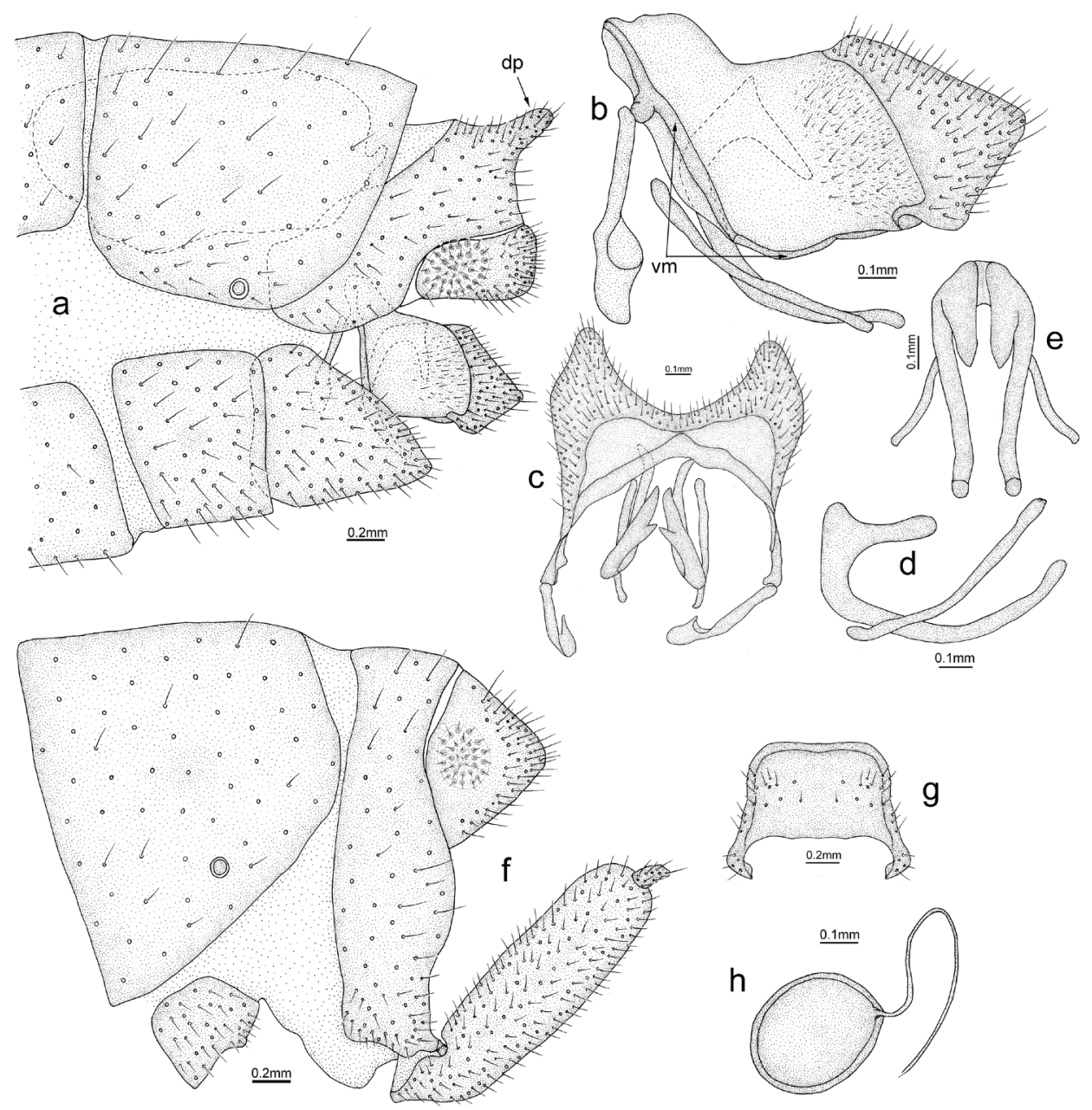

Figure 9. Osmylus angustimarginatus sp. n. a-e Male: $\mathbf{a}$ apex of the abdomen and genitalia $\mathbf{b}$ genitalia, lateral view $\mathbf{c}$ genitalia, dorsal view $\mathbf{d}$ mediuncus, lateral view $\mathbf{e}$ mediuncus, dorsal view $\mathbf{f}-\mathbf{h}$ Female: $\mathbf{f}$ apex of the abdomen and genitalia $\mathbf{g}$ subgenital plate, ventral view $\mathbf{h}$ spermatheca, lateral view. Abbreviations: $\mathrm{dp}$, dorsal process; vm, ventral margin.

Distribution. Known only from Chongqing, China.

Etymology. The specific name 'angustimarginatus' the compound of Latin deribation, from angusti- (narrow) and marginatus- (margin), refers to the well sclerotized ventral margin of the gonarcus in lateral view.

Remarks. The dorsal process of $9^{\text {th }}$ tergite in the male of $O$. angustimarginatus sp. n. is finger-like (Fig. 9a), closely resembling the condition observed in O. maoershanicola sp. n. However, the ventral margin of the gonarcus of $O$. angustimarginatus sp. $\mathrm{n}$. is well sclerotized (Fig. 9b), clearly differentiating it from O. maoershanicola sp. n. Moreover, female gonapophysis lateralis of $O$. angustimarginatus sp. n. is more slender in comparison with the fusiform gonapophysis lateralis of $O$. maoershanicola sp. n. (Fig. 5f). 


\section{Acknowledgements}

We sincerely thank Zhang Weiwei (Beijing) for collecting the specimens. This research is supported by the National Natural Science Foundation of China (grants 31272352, 31301905 and 41372013), the China Postdoctoral Science Foundation (grant 2012T50113), the Beijing Natural Science Foundation (grant 5132008), and Ph.D. Programs Foundation of Ministry of Education of China (grant 20131108120005).

\section{References}

Adams PA (1969) A New Genus and Species of Osmylidae [neuroptera] from Chile and Argentina, with a Discussion of Planipennian Genitalic Homologies. Postilla 141: 1-11. doi: 10.5962/bhl.part.24591

Banks N (1913) Synopses and descriptions of exotic Neuroptera. Transaction of the American Entomological Society 39: 201-242. http://www.jstor.org/stable/25076911

Banks N (1947) Some neuropterous insects from Szechwan, China. Fieldiana: Zoology, Chicago Natural History Museum 31: 99. doi: 10.5962/bhl.title.2821

Canbulat S (2013) Redescription of Osmylus multiguttatus McLachlan, 1870 (Neuroptera: Osmylidae) with distributional remarks. Zootaxa 3741(3): 385-390. doi: 10.11646/ zootaxa.3741.3.7

Devetak D, Duelli P (2007) Intestinal contents of adult Osmylus fulvicephalus (Scop.) (Neuroptera, Osmylidae). Annales for Istrian and Mediterranean Studies, Series Historia Naturalis 17: 93-98. http://www.dlib.si/stream/URN:NBN:SI:DOC-5XYMHHIP/f7db0a9c547e-4e38-8bf6-2bc28353e082/PDF

Eisner M (1989) Biologie und Larvalmorphologie der wasserlebenden Neuropteren Mitteleuropas (Neuropteroidea; Megaloptera, Planipennia). PhD Thesis, University Graz, Graz.

Iwata M (1928) A new hemerobiid larva (Neuroptera), Osmylus kisoensisn. sp. Kontyû 2:215-220. http://lacewing.tamu.edu/neuropterida/neur_bibliography/edoc12/iwata1928ref3111-340. pdf

Kozhanchikov IV (1951) New Asiatic species of Osmylidae (Neuroptera). Entomologicheskoe Obozrenie 31: 523-528.

Krüger L (1912) Osmylidae. Beiträge zu einer Monographie der Neuropteren-Familie der Osmyliden. I. Osmylus chrysops L. Stettiner Entomologische Zeitung 73:319-373. http://lacewing.tamu.edu/neuropterida/neur_bibliography/edoc12/kruger1912ref3464s-2148.pdf

Krüger L (1913) Osmylidae. Beiträge zu einer Monographie der Neuropteren-Familie der Osmylidae. Stettiner Entomologische Zeitung 74: 3-123. http://lacewing.tamu.edu/neuropterida/neur_bibliography/edoc12/kruger1913ref3465s-2253.pdf

Kuwayama S (1953) The insect fauna of Mt. Ishizuchi and Omogo Valley, Iyo, Japan: Neuroptera. Transaction of Shikoku Entomological Society 3: 177-180.

Kuwayama S (1962) A revisional synopsis of the Neuroptera in Japan. Pacific Insects 4: 325-412. Latreille PA (1805) Histoire naturelle, générale et particulière des crustacés et des insectes (Vol. 13). F. Dufart, Paris, 432 pp. http://lacewing.tamu.edu/neuropterida/neur_bibliography/ edoc12/latreille1805ref3639-5194.pdf 
Makarkin VN (1985) Review of the family Osmylidae (Neuroptera) of the fauna of the USSR. In: Lehr PA, Storozhenko SYu (Eds) Taxonomy and ecology of arthropods from the Far East. Far Eastern Scientific Centre, Vladivostok, 35-47.

McLachlan R (1870) New species etc. of Hemerobiina-second series (Osmylus). Entomologist's Monthly Magazine 6: 195-201. http://lacewing.tamu.edu/neuropterida/neur_bibliography/edoc12/mclachlan1870ref350-345.pdf

McLachlan R (1875) A sketch of our present knowledge of the neuropterous fauna of Japan (excluding Odonata and Trichoptera). Entomological Society of London 23: 179-181. doi: 10.1111/j.1365-2311.1875.tb01906.x

Nakahara W (1914) On the Osmylinae of Japan. Annotationes Zoologicae Japonenses 8: 489-518.

Navás L (1910) Osmylides exotiques (insectes névroptères) nouveaux. Annales de la Société Scientifique de Bruxelles 34: 188-195. http://lacewing.tamu.edu/neuropterida/neur_bibliography/edoc12/navas1910ref517-347.pdf

New TR (1983) A revision of the Australian Osmylidae: Kempyninae (Insecta: Neuroptera). Australian Journal of Zoology 31: 393-420. doi: 10.1071/ZO9830393

New TR (1991) Osmylidae (Insecta: Neuroptera) from the Oriental Region. Invertebrate Taxonomy 5: 1-31. doi: 10.1071/IT9910001

Sekimoto S (2011) Revision of the genus Osmylus (Neuroptera: Osmylidae: Osmylinae) of Japan. Insecta matsumurana. Series entomology. New series 67: 1-22. http://eprints.lib. hokudai.ac.jp/dspace/bitstream/2115/47450/1/01\%20Sekimoto.pdf.pdf

Stein F (1838) Entwicklungs-Geschichte mehrere Insektengattungen aus der Ordnung der Neuropteren. Archiv für Naturgeschichte 4: 315-333.

Von Johann GEPP (1976) Die Neuropteren von Graz: Ein Beitrag zur Kenntnis der mitteleuropäischen Großstadtfauna.-Mitt. Naturwiss. Ver. Steiermark 105: 265-278. http:// www.zobodat.at/pdf/MittNatVerSt_105_0265-0278.pdf

Wang YJ, Liu ZQ (2009) Two new species of Parosmylus Needham (Neuroptera, Osmylidae) from China, with a key to Chinese species. Zootaxa 1985: 57-62. http://mapress.com/ zootaxa/2009/f/z01985p062f.pdf

Wang YJ, Liu ZQ (2010) New species of Osmylus Latreille from Henan, China (Neuroptera: Osmylidae). Zootaxa 2363: 60-68.

Withycombe CL (1923) XX - Notes on the Biology of some British Neuroptera (Planipennia). Transactions of the Royal entomological Society of London 70(3-4): 501-594. doi: 10.1111/j.1365-2311.1923.tb02844.x

Yang CK (1987) Neuroptera. In: Zhang S (Ed.) Agricultural insects, spiders, plant diseases and weeds of Xizang. Vol. 1. Xizang Renmin Press House, Tibet, China, 191-194.

Yang CK (1988) Neuroptera: Osmylidae, Dilaridae, Hemerobiidae, Chrysopidae, Mantispidae, Myrmeleontidae, Ascalaphidae, Corydalidae. In: Huang FS (Ed.) Insects of Mt. Namjagbarwa region of Xizang. Science Press, Beijing, China, 195-196.

Yang CK (1997) Neuroptera: Osmylidae. In: Yang XK (Ed.) Insects of the Three Gorge Reservoir Area of Yangtze River. Chongqing Press, Chongqing, China, 580-581.

Yang CK (1999) Osmylidae. In: Huang BK (Ed.) Fauna of Insects Fujian Province of China Vol. 3. Fujian Science and Technology Press, Fuzhou, China, 96-98. 